\title{
A ADOLESCÊNCIA PERDIDA: CORPO E PERVERSÃO NO CINEMA DE LARRY CLARK
}

Henrique Codato ${ }^{1}$

\section{Introdução}

A adolescência remete em questão o passar do tempo, pois anuncia a mudança de estado sofrida por um corpo ao abandonar gradativamente a condição infantil para atingir a idade adulta - não mais criança e ainda não adulto - revelando, com isso, uma espécie de intersecção marcada por uma relação bastante particular entre o passado e o futuro, vivida por um corpo que parece estar completamente enclausurado no presente. Ao discutir a adolescência, o psicanalista André Green (2000) fala-nos, justamente, de um "tempo morto", que corresponde à tentativa de imobilizar o tempo que passa na perspectiva do devir adulto e, simultaneamente, de fazê-lo avançar, o mais depressa possível, a fim de abandonar o estado infantil.

Filmar a adolescência e o corpo adolescente tem sido o gesto primordial de diversos diretores do cinema contemporâneo: Gus Van Sant; Sofia Coppola; Bernardo Bertolucci; Richard Linklater; Xavier Dolain; os brasileiros Domingos de Oliveira e Lais Bodanzky; enfim, a lista é extensa. Nesse sentido, propomos levantar e problematizar algumas questões acerca da imagem da adolescência a partir de uma visita a três filmes do fotógrafo e cineasta estadunidense Larry Clark. Suas obras que aqui nos interessam - Kids (1995); Ken Park (2002) e O Cheiro da Gente (Smell of us, 2015) - são, sem dúvida, os mais conhecidos, polêmicos e controversos trabalhos de Clark no cinema, e compõem (ou, pelo menos, assim entende boa parte da crítica especializada) uma espécie de retrato cinematográfico geracional $^{2}$ da juventude nas três últimas décadas, do mesmo modo, quiçá, que o conjunto de seus trabalhos fotográficos - com destaque aos emblemáticos Tulsa (1971) e Teenage Lust (1983) - também sirva, de algum modo, para testemunhar sobre os hábitos de uma determinada época, de um determinado grupo de adolescentes, captados em meio à banalidade de seu cotidiano,

\footnotetext{
${ }^{1}$ Universidade Federal do Ceará, Brasil.

${ }^{2}$ Em janeiro de 2017, a Revista Vice dedica a Clark uma longa reportagem por ocasião de seu $74^{\circ}$ aniversário, nomeado de oráculo da juventude. Uma versão online da matéria traduzida para o português pode ser encontrada em: https://www.vice.com/pt_br/article/larry-clark-impactou-cultura-jovem. Consultada em 21 de maio de 2017.
} 
que envolve muito sexo, álcool e drogas injetáveis.

Quanto a seus filmes, é possível defender, por um lado, que eles se referem a uma comunidade bastante específica - os chamados skaters, integrantes de uma subcultura que nasce nos EUA, em torno da prática do skate e do uso de drogas, principalmente da maconha - que se propaga mundo afora por meio da música (Nirvana e Kurt Cobain, Bad Religion, Green Day e NOFX, por exemplo) e da moda (camisetas e calças largas, roupas íntimas à vista, boné virado para trás), com uma estética que vai posteriormente influenciar o movimento hip hop, o funk e o rap. No entanto, apesar das especificidades dessa dita comunidade, há algo de incontestavelmente universal nessas narrativas e é desse elemento comum que gostaríamos de partir no desenvolvimento de nossas reflexões. Todas elas falam da adolescência - esse "tempo extraordinário em que as pessoas desconhecem que estão verdadeiramente a viver", como definiu belamente o cineasta Manoel de Oliveira ${ }^{3}$-; período da vida marcado por profundas transformações, tanto exteriores ( $d o$ e no corpo), quanto interiores (da vida subjetiva).

Interessa-nos, pois, refletir como Clark se serve do signo da adolescência e da figura do adolescente em seus trabalhos. Não se trata exatamente de analisar sua representação no âmbito da diegese, mas, sim, de tentar compreender a economia sensível que suas obras colocam em cena quando se propõem a retratar a adolescência; analisar os modos de endereçamento do olhar que sua câmera constrói ao filmar o corpo vivo e em transformação dos adolescentes. Nossa hipótese é a de que o cinema de Clark opera a partir de uma mecânica perversa; entendendo a perversão, aqui, menos como uma estrutura de personalidade (como reza o pensamento psicanalítico), mas como uma estratégia retórica, naquilo que sua etimologia mesmo indica: per: totalmente, e vertere: virar. Em termos deleuzianos, poderíamos dizer que se trata de uma "intrínseca transformação de energia" que tem o mérito de "trazer o corpo para o campo do pensamento" (Deleuze, 2009: 28).

Para Gilles Deleuze (2002: 353), a perversão não se define pela força de um desejo no sistema de pulsões, pois o perverso não é aquele que deseja, mas, ao contrário, é aquele que introduz o desejo em outro sistema, fazendo-o assumir, nessa nova configuração de forças, o papel de um limite interior, uma espécie de "ponto zero" da

\footnotetext{
${ }^{3}$ Em entrevista à Fundação Calouste Gulbenkian, por ocasião do $99^{\circ}$ aniversário do diretor português. Disponível em: http://www.fenprof.pt/?aba=57\&cat=185\&doc=3002\&mid=123. Consultado em 21 de maio de 2017.
} 
experiência. Dito de outro modo, defendemos que a perversão, para além de um desvio normativo, torna-se, nas narrativas clarkeanas, uma manobra estilística possível de capturar na própria forma fílmica; algo que constrange o leitor/espectador e que se revela (ou que se esconde) nos modos de endereçamento/enquadramento do olhar lançado sobre esses adolescentes, na maneira de inscrever a matéria elástica e inacabada de seus corpos no espaço do filme.

Nessa perspectiva, sistematizamos nosso estudo em quatro partes distintas. As três primeiras visam analisar cada um dos trabalhos de Clark escolhidos como objeto, buscando elencar elementos singulares que emergem de nossa experiência com o filme. A última parte, por sua vez, é dedicada a uma breve conclusão, entrecruzando essas narrativas a fim de entender de que modo o olhar perverso do diretor as atravessa e costura a partir da temática maior da adolescência e da figuração do corpo adolescente no espaço da cena filmada.

\section{Kids}

Kids, feito em 1995, é a primeira produção feita por Clark para o cinema. Baseado no roteiro original do jovem Harmony Korine ${ }^{4}$, em tom documental, naturalista, próximo ao do cinema vérité, e com uma narrativa bastante fragmentada, o filme "é resultado de toda uma pesquisa comportamental e iconográfica desenvolvida pelo diretor ${ }^{5 "}$ (Oliveira Jr., 2013) e mostra um dia na vida de um grupo de jovens skatistas, habitantes dos subúrbios de Nova York ${ }^{6}$. As sequências do filme operam de maneira quase autônoma, mas descortinam, como numa colagem, o panorama de um universo sem profundidade ${ }^{7}$, permeado de sexo, drogas, álcool, violência e

\footnotetext{
4 “Kids" foi o primeiro roteiro filmado de Korine, então com apenas 19 anos. Dez anos depois, ele voltará a colaborar com Clark no roteiro de Ken Park.

${ }^{5}$ Disponível em: http://www.contracampo.com.br/59/kids.htm. Consultado em 21 de maio de 2017.

${ }^{6}$ Contextualmente, é importante lembrar que em meados da década de 1990, o então prefeito de Nova York, o republicano Rudolph Giuliani, implementa na cidade um efetivo programa de combate às drogas em razão do crescimento avassalador do uso de crack entre os jovens de baixa renda nos Estados Unidos. O programa, conhecido como Broken Windows, visava o aumento do efetivo policial na cidade a fim de estabelecer uma política de tolerância zero ao uso de drogas. As ações de repressão acarretam um notável aumento no número de presos - principalmente de jovens habitantes dos subúrbios e de negros -, o que acaba por gerar duras críticas, principalmente por parte dos intelectuais de esquerda e do meio universitário, que apontavam para o caráter racista, higienista e excludente do programa de Giuliani.

${ }^{7}$ Referimo-nos, aqui, tanto à ausência de profundidade de campo nas cenas filmadas, quanto ao caráter superficial que o filme coteja ao oferecer um retrato do cotidiano desses jovens.
} 
marginalidade. Clark escolhe trabalhar com atores não profissionais (o que continuará a ser uma das principais características de seu cinema), retratando-os em sua intimidade e em seu cotidiano (que inclui, basicamente, fumar, beber e falar sobre sexo), sempre com uma câmera bastante inquieta e curiosa ${ }^{8}$, tal como deve ser um adolescente, poderíamos dizer.

Na história do cinema, a adolescência surge indissociável da representação das diferentes crises vividas pela sociedade. Para Calvet e Vasse (2007), o cinema coloca em cena a adolescência no sentido quase orgânico de um conflito entre o agora e seu devir mortífero, idade de recusa de valores e limites ${ }^{9}$. Luiz Carlos de Oliveira Jr. (2013) defende, no entanto, que o filme de Clark desconstrói a visão romântica do adolescente até então mostrada por Hollywood e pelos seriados de TV, geralmente interpretado por atores mais velhos. Ao trazer em cena adolescentes de verdade, a intenção de Clark, segundo Oliveira Jr., seria o de revelar "uma adolescência que não está sendo vista, negligenciada pelos adultos ${ }^{10}$, , captada da forma crua e pretensamente realista.

Em Kids, a realidade dos adultos é retratada de forma degradante, miserável, como no caso da solitária mãe de Telly - único progenitor a aparecer efetivamente em cena - que amamenta o filho pequeno enquanto fuma, subjugada às tarefas do lar; ou do homem sem pernas, que rasteja pelos vagões do metrô pedindo esmolas. De fato, parece não haver comunicação possível entre estes dois mundos, como atesta a conversa entre Jennie (Chloé Sevigny) e o motorista de táxi falastrão que a conduz pela cidade à procura de Telly (Leo Fitzpatrick). Com efeito, ainda que recheados de palavrões, injúrias e adjetivos pejorativos (bitch, nigger, asshole, faggot ${ }^{11}$ ), os diálogos no filme parecem nada querer dizer; são esvaziados de sentidos, com pouca ou nenhuma relevância para o andamento da história filmada.

\footnotetext{
${ }^{8}$ Tributária, em larga medida, do trabalho da handycam de Eric Alan Edwards, diretor de fotografia do filme.

${ }^{9}$ Para Calvet e Vasse (2007), o personagem mítico de James Dean em Juventude Transviada (Rebel without a cause, Nicholas Ray, 1955) é a "entrada oficial do adolescente no campo do cinema americano" (Calvet e Vasse, 2007: 7); momento, segundo eles, que o cinema americano começa a fazer sua autocrítica face ao crepúsculo de seus ídolos, deixando transparecer, no espaço da tela, as falhas existenciais de seus personagens, bem como as falhas econômicas e paradigmáticas de seu sistema de produção.

${ }^{10}$ Idem.

${ }^{11}$ Em uma tradução aproximada, "puta”, "preto", “cuzão" e "viado”, respectivamente. Nossa tradução.
} 
Quanto a ela, eis o mote: Telly (Leo Fitzpatrick), um garoto franzino, de 16 anos, é um deflorador de virgens que acaba contaminando Jennie (Chloé Sevigny), da mesma idade, com o vírus HIV em sua primeira relação sexual. Após um exame, ao saber-se soropositiva, desesperada, a jovem sai pela cidade em busca do garoto, e após uma longa peregrinação (que inclui a casa dos pais de Telly, a casa de um de seus amigos, a pista de skate que frequentam, uma boate de música eletrônica e, finalmente, uma festa na casa de um outro jovem, cujos pais estão em viagem) ela acaba por encontrá-lo na cama com outra menina, outra virgem com quem também transa sem proteção. Exausta e sob o efeito de um ácido que ganhara mais cedo de um amigo na boate (interpretado pelo próprio Harmony Korine, roteirista do filme), Jennie adormece no sofá da casa, em meio aos outros jovens que também dormem, e é abusada pelo melhor amigo de Telly, Casper (Justin Peirce), enquanto desacordada.

Fruto de imensa polêmica, Kids vem suscitar como questão central os limites do corpo e da sexualidade, grande dilema da chamada "Geração X", que viveu/sobreviveu ao advento da AIDS e construiu sua sexualidade sob o peso das metáforas estigmatizantes associadas à síndrome, entendida como um "castigo individual-coletivo inscrito na metáfora da peste", nas palavras de Susan Sontag (1990: 133). Idealizado ao extremo, o sexo opera no filme como significante de um fantasma ${ }^{12}$, que revela o corpo do outro como enigma a ser jamais elucidado, território a ser ficcionalizado, explorado, mas nunca conquistado totalmente (ainda que, na sequência final da festa, vejamos o quão insistente um rapaz pode ser quando quer levar uma menina para a cama). A nudez é um tanto contida, nunca explícita, mas sempre dissimulada pelos calções largos dos meninos, que circulam, na maior parte do tempo, de peito nu, e pelos sutiãs transparentes das meninas. O quadro impõe-se, no mais das vezes, como limite, barreira intransponível que impede o olhar do espectador a acessar por inteiro o corpo filmado, geralmente cortado na altura da cintura (Figura 1), ou servido, ele mesmo, como obstáculo para a nudez que se busca registrar (Figura 2).

\footnotetext{
${ }^{12}$ Considerado, em termos lacanianos como uma função epistemológica mediadora entre a realidade e o Real. O fantasma opera de modo a encobrir o objeto do desejo com uma trama ficcional. Para saber mais, sugerimos a leitura do Seminário XIV de Jacques Lacan, intitulado A Lógica do fantasma.
} 


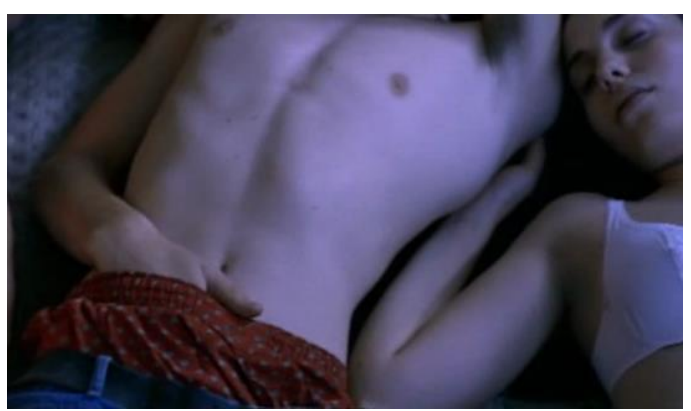

Figura 1

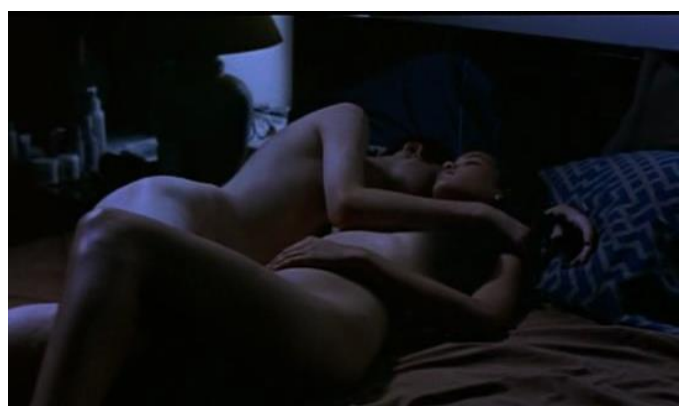

Figura 2

É bastante notável a divisão de gêneros entre os kids: meninas de um lado, meninos de outro. Essa separação fica evidente, por exemplo, nas idas e vindas da sequência que mostra os dois grupos conversando sobre sexo. Para o crítico estadunidense David Denby (1995), entretanto, longe de conseguir mostrar um retrato fiel desses adolescentes, Clark, aqui, “expõe sua própria erotomania, uma fantasia de ininterrupta excitação ${ }^{13}$ " (Denby, 1995: 44). Com efeito, estamos em um universo essencialmente heteronormativo, machista e falocêntrico, no qual a homossexualidade masculina parece não ter espaço, como mostra a reação dos meninos ao agredirem verbalmente dois homens que passam de mãos dadas pelo parque onde se reúnem, ao passo que a homossexualidade feminina - vemos duas das garotas do grupo se beijarem na sequência em que alguns dos jovens invadem a piscina fechada de uma escola parece somente servir para contentar/provocar o olhar masculino (dos personagens e também do espectador). Como sublinha Henri Giroux:

(...) as meninas do filme seguem a liderança dos personagens masculinos, silenciosamente observam suas expressões de brutalidade e se derramam em lágrimas quando elas se tomam os objetos de sua violência. Uma sexualidade predatória permeia o impiedoso mundo dos misóginos adolescentes masculinos, adolescentes saturados por sua auto-importância e por seu desejo de caçar as garotas, as quais passivamente esperam ser empurradas para um ritual de sedução e possivelmente de morte. (Giroux, 1995: 128)

\footnotetext{
${ }^{13}$ No original: "Clark (...) is offering not a faithful portrait of teenagers but an exposure of his own erotomania, a fantasy of perpetual arousal". Nossa tradução.
} 
No mesmo sentido, Giroux (1995) também destaca certo caráter racista em Kids ao afirmar que os efeitos das representações dos jovens afro-americanos no filme reforçam e perpetuam um discurso de preconceito, refletindo as práticas excludentes que condicionam o papel da juventude negra nos Estados Unidos, numa época em que esta população passa a enfrentar massivos ataques por parte da parcela mais conservadora da sociedade estadunidense ${ }^{14}$. Para Giroux (1995: 131), embora Casper e Telly sejam brancos, eles se comunicam por meio da gíria negra das ruas, assim como suas vestimentas reproduzem a moda cultural negra do hip-hop. Os personagens negros não são exatamente centrais em Kids - ainda que sejam maioria no filme - e são retratados ou como vítimas de violência, como acontece com o garoto espancado por Casper e seus amigos, ou, então, encarnam a expressão de certos estereótipos sexuais, tal como evidencia a já mencionada sequência da piscina, em que um dos garotos negros exibe aos colegas brancos seu pênis, cujo tamanho é motivo de surpresa e admiração $^{15}$.

De todo modo, Clark aposta que todos esses meninos e meninas pensam e falam sobre uma única e mesma coisa: sexo. Embora no filme as cenas de sexo propriamente dito sejam poucas, o tema permeia as conversas cheias de curiosidade (entre os meninos mais velhos e os mais novos, entre as meninas, entre os casais); orienta os gestos (os garotos estão, todo tempo, com uma das mãos a tocar o pênis, seja por dentro ou por fora da roupa); enfim, o sexo é, com efeito, onipresente, tal qual a fumaça dos baseados e dos caretas que circulam por entre os mais velhos e os mais jovens. Quanto a essa geração mais nova, Denby (1995) afirma que seu futuro é pressagiado tanto pelo quarteto de pré-adolescentes que bebem e fumam até a inconsciência durante a festa que conclui o filme (Figura 3), quanto pela imagem de uma garotinha que, em companhia de sua boneca, vê Jennie chegar à casa de Telly (Figura 4). "É tudo uma questão de tempo", parece dizer Clark ao espectador (Denby, 1995), sublinhando, com isso, um espelhamento entre o presente e o porvir.

\footnotetext{
${ }^{14}$ Ver nota de rodapé no. 6.

${ }^{15} \mathrm{Na}$ cena em questão, o rapaz tira o calção de banho e começa a saltar. Apesar de não vermos sua nudez, ouvimos os ruídos de seu pênis subir e descer, batendo contra a pele do jovem, que sorri orgulhoso. Enquanto isso, os outros meninos e meninas fazem comentários sobre o tamanho avantajado do membro do amigo.
} 


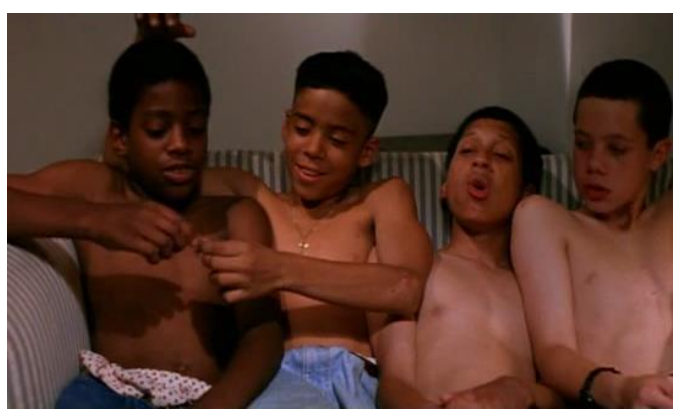

Figura 3

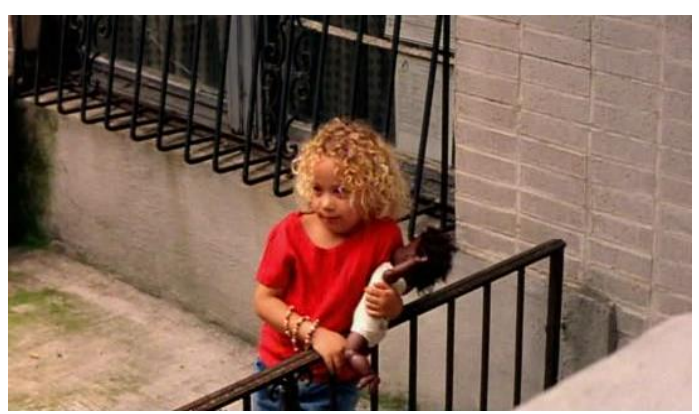

Figura 4

Em Kids, a perversão não está somente na caça às virgens executada por Telly, na visão subversiva dos meninos em relação às meninas; nos furtos cometidos na mercearia do comerciante chinês; ou no espancamento sofrido pelo jovem negro que se indispõe com Casper na pista de skate. Ela não é apenas um privilégio ou uma arma dos adolescentes filmados. A perversão conduz o olhar da câmera de Clark, que brinca com o corpo desses jovens e com o olhar do espectador de modo a guiá-los como deseja, ao seu bel prazer. Luis Carlos de Oliveira Junior (2013) chega a afirmar que os jovens do filme são como "ratinhos de laboratório, aos quais se dão todo tipo de substância química e de estímulo sensorial (...) resultando no imobilismo absoluto (...) um eterno agora que, é visto como inércia ao longo prazo e, em última instância, em morte precoce". Eis, quiçá, a maior perversão que o olho mecânico da câmera tenta captar: por trás desses corpos jovens, que despertam curiosidade e desejo, não há nada. Para Clark, eles não passam de fantasmas de seus próprios fantasmas - perdidos, sem saber que "vivem de verdade", para voltarmos às palavras de Manoel de Oliveira.

\section{Ken Park}

Já Ken Park é um filme mais comercial e didático. Embora elaborado nos mesmos moldes de Kids - ou seja, bastante próximo da linguagem documentária, trazendo em cena tanto atores profissionais (os adultos, ausentes no primeiro filme) quanto não profissionais (no caso, os jovens adolescentes protagonistas), novamente abordando o cotidiano de um grupo de skaters, dessa vez na Califórnia, na cidadezinha de Visalia - o segundo filme de Larry Clark parece-nos mais clássico (e, portanto, mais narrativo), mais preciosista, mais asséptico, e, igualmente, mais bem conduzido. Quiçá, 
muito em razão da parceria de Clark com Edward Larchman, diretor de fotografia, que codirige a obra, roteirizada, de novo, por Harmony Korine.

A história começa com o suicídio filmado de um jovem - justamente Ken Park (ou Krap Neck ${ }^{16}$, interpretado por Adam Chubbuck) - que dá um tiro na cabeça no alto de uma pista de skate, em meio a outros frequentadores do local, diante de uma câmera portátil preparada pelo próprio suicida. Voltaremos a encontrá-lo na sequência final do filme, primeiramente com seu pai - interpretado pelo próprio Clark - preparando hot dogs; em seguida, sentado em um banco de praça, diante da mesma pista de skate que servira de palco para sua morte, a conversar com a namorada. Neste momento, descobrimos o aparente motivo do suicídio do garoto: a moça espera um filho seu. Os dois discutem sobre a possibilidade de terem ou não a criança. "Você não está feliz da sua mãe não ter te abortado?", pergunta ela ao rapaz. Ele hesita, mas nada responde, ao passo que a câmera se fixa sobre seu rosto reflexivo por alguns segundos. Fim do filme.

Notemos, assim, a circularidade da narrativa de Ken Park, que se inicia e se conclui com a figura emblemática do garoto que dá nome à obra. Tal movimento circular talvez seja uma alegoria do enclausuramento vivido por esses adolescentes diante do comportamento abusivo e destrutivo dos adultos que os cercam. O gesto de filmar a própria morte parece-nos também um prenúncio da obsessão de tudo registrar que se tornará tendência nas décadas seguintes, com a popularização massiva dos smartphones, o surgimento do selfie e o hábito de produzir vídeos e fotos de atividades banais do cotidiano, fazendo-os circular em aplicativos e redes sociais ${ }^{17}$. O tema, aliás, como veremos, torna-se central em $O$ Cheiro da gente, terceiro filme de Clark que nos interessa nesse estudo.

Ao passo que em Kids éramos aos poucos inseridos na vida dos personagens, em Ken Park as apresentações são feitas pelos próprios protagonistas, em voz off (um pouco como naquelas dinâmicas de grupo, nas quais temos de introduzir o colega ao lado), logo no início do filme. Enquanto isso, num exercício extremo de didatismo, o espectador vê imagens (em movimento, mas também fotografias) do personagem cuja voz sem corpo introduz e descreve. Sabemos, pois, onde estamos e com quem lidamos. Desse modo, o filme dedica-se às relações interpessoais, pontuado por uma série de

\footnotetext{
${ }^{16}$ Numa aproximação, algo como Pescoço Podre em português. Trata-se de um trava-línguas elaborado a partir do nome do jovem. Nossa tradução.

${ }^{17}$ Como Facebook, Instagram, Snapchat, entre outros.
} 
conflitos familiares vividos por Shawn (James Bullard), Claude (Stephen Jasso), Peaches (Tiffany Limos) e Tate (James Ransone), que incluem traição, abuso, assédio, violência, morte e fanatismo religioso, e mostrando-nos a adolescência como o reflexo de uma sociedade vil, triste e degradante.

Ainda sobre o caráter didático do filme, os exemplos são abundantes. Algumas de suas sequências se relacionam por meio de metáforas visuais - como na cena que antecede o assassinato dos avós de Tate, que mostra o garoto nu, a cortar uma fatia de bolo na cozinha, encaminhando-se em seguida para o quarto do casal para esfaqueá-los -; ou, então, por analogia - como na passagem em que vemos, em primeiro plano, a imagem de um crucifixo que pende do pescoço de um dos jovens enquanto fuma maconha e discute com outros adolescentes (Figura 5), enquanto a cena seguinte mostra o pai de Peaches (Julio Oscar Mechoso) no cemitério, a visitar o túmulo de sua esposa, cuja lápide traz, justamente, a insígnia da cruz (Figura 6). Poderíamos mencionar ainda a sequência em que Peaches e o namorado são surpreendidos na cama pelo pai da moça, que mostra o pênis do jovem "saltar" para fora de seu calção ao mesmo tempo em que a bíblia que o progenitor segura cai de suas mãos, num movimento de plano/contraplano igualmente marcado por uma sincronia sonora ${ }^{18}$.

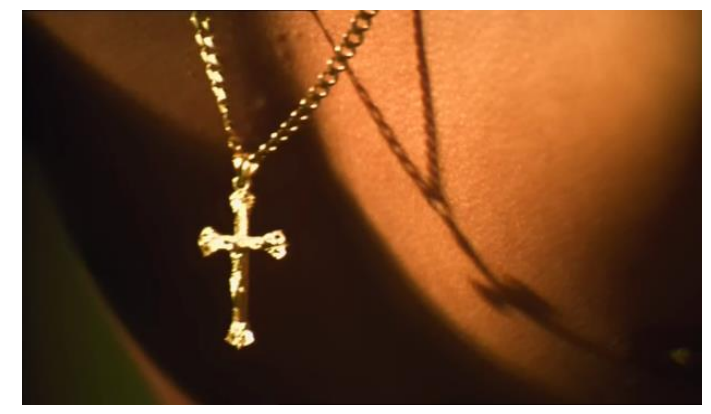

Figura 5

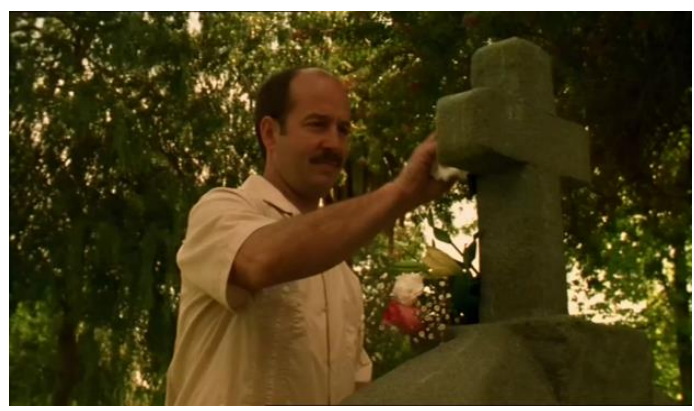

Figura 6

Se, em Kids, os adultos estavam quase ausentes da cena, eles aparecem em Ken Park como figuras de autoridade enfraquecidas ou falidas; adolescentes tardios, sempre um tanto patéticos e completamente inaptos para educarem sua prole. No mais das vezes, eles operam como obstáculo a ser contornado - como no caso de Peaches e seu pai ultrarreligioso, ou Claude e seu pai hipócrita, violento e repressor - ou, então, devem ser

\footnotetext{
${ }^{18} \mathrm{O}$ som do membro ereto do rapaz ao saltar do calção e chocar-se contra a pele de seu abdômen é simultâneo ao som da bíblia que, ao cair das mãos de pai de Peeches, toca o chão do quarto.
} 
abatidos, aniquilados- como faz Tate, literalmente, com seus avós. Aí reside, quiçá, a mais notável perversão do filme: Clark desvela a frustração da vida adulta, aponta sua incapacidade de lidar com o futuro e especula (em seu duplo sentido: o de explorar, mas também o de fazer ver) o desejo de retornarmos a um momento da vida no qual ainda é possível imaginar/sonhar com outros destinos, outros horizontes, outros gostos, outra vida, quem sabe numa Ilha do Paraíso, onde se possa "trepar o dia todo"; tal como devaneiam Claude, Peaches e Shawn no final da história, em seu idílico ménage.

Em Ken Park, Clark explora, em larga medida, os fantasmas que já assombravam seu primeiro filme, porém, dessa vez, colocando-os em cena. Se, em Kids, o que chocava era o discurso absolutamente sem censura dos adolescentes sobre sexualidade, muito mais do que as parcas cenas de sexo simulado e da nudez parcial mostradas na obra, o que talvez choque em Ken Park é exatamente o contrário: aqui, as cenas de sexo são explícitas (ainda que simuladas), registradas por meio de uma câmera contemplativa e voyeurista, embora pouco se fale sobre ele. Experimentar o corpo do outro adquire, pois, uma conotação quase redentora para esses jovens de Visalia. A fim de escapar de seus dramas pessoais e familiares, é no sexo que esses adolescentes encontram refúgio e alguma possibilidade de vida e de liberdade. Assim, em Ken Park, o corpo passa a ser o lócus de uma experimentação erótica estetizada, estilizada, próxima da pornográfica, assumindo, às vezes, ares de grotesco - como no caso da cena de masturbação/enforcamento de Tate (Figura 7) - noutras, publicitário - como na já destacada sequência do ménage (Figura 8).

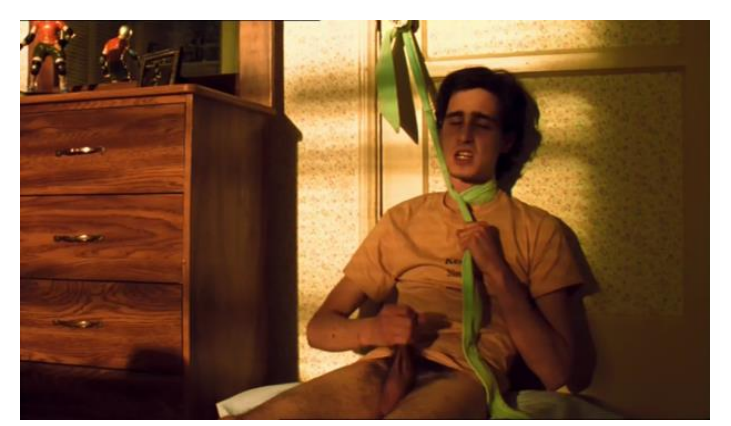

Figura 7

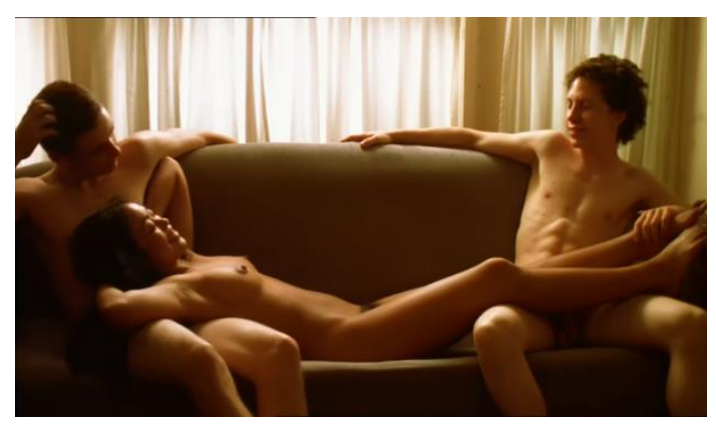

Figura 8 
Filmada em câmera lenta, numa alternância de planos gerais e de primeiros planos - dos pés, mãos, lábios, mamilos - e embalada por uma canção romântica country $^{19}$, a sequência do ménage revela a importância do plano detalhe na elaboração da mise-en-scène de Ken Park. Para Anna Muslewski (2013), a câmera tátil e intrusiva de Clark cola-se aos corpos filmados, ao passo que o excesso de visibilidade que a cena produz é paradoxalmente construído por meio da fragmentação do instante, determinando, assim, o ritmo da passagem de um plano para outro. Tal artifício promove um efeito de longa duração para a cena, estendendo o tempo da narrativa e ocasionando uma sensação de proximidade entre espectador e personagens.

O ménage é entrecortado por momentos de diálogo, em que ouvimos Shawn, Claude e Peaches conversarem sobre seus sonhos e desejos escapistas e brincando de “quem sou eu?", enquanto os vemos acariciar e explorar seus respectivos corpos, que se embaralham no espaço da cena. Nesse jogo de adivinhação, Shawn é o líder, e suas pistas nos levam a entender que a personagem misteriosa sobre a qual pensa é um de seus amigos, "alguém que não mais está entre nós", diz ele. "Tate?”, pergunta Peaches. "Não", responde Shawn. "Então ele está morto?”, arrisca Claude. "Sim”, sentencia o líder. Trata-se, é claro, de Ken Park, o jovem suicida. Afinal, todos esses jovens - ou qualquer um deles - poderiam ser, de algum modo, Ken Park; é o que parece nos querer dizer Larry Clark.

No caso da cena da masturbação/estrangulamento de Tate, ela prenuncia a violenta sequência em que o garoto mata seus avós. Há de se notar, nesse sentido, um rompimento com o caráter erótico da imagem, num esforço de infringir ao espectador certa repugnância, relevando, com isso, o sentimento de abjeção que ela promove. A cena é longa e alterna planos gerais a primeiros planos do rosto de Tate, que perde gradativamente o fôlego, à medida que aperta o laço envolvendo seu pescoço; de seu órgão sexual em excitação; e de um aparelho de TV, cuja imagem mostra uma partida de tênis feminino, e cujo som - uma sucessão de gemidos emitidos pelas jogadoras ao receberem e relançarem a bola - atravessa a diegèse, funcionando como uma espécie de trilha sonora para a cena. Se o abjeto se mostra por meio do excesso de realidade, pelo sentido que entra em colapso, como supõe Julia Kristeva (1982), a imagem, aqui, não tem anteparos: a saliva que se aglomera nos cantos da boca do adolescente em agonia é

${ }^{19}$ Trata-se de Shaddy Streets, do cantor estadunidense Gary Stewart. 
verdadeira; o jato de sêmen que explode de seu membro ereto, também. Assim, num tempo dilatado, equivalente àquele da vida, a exposição do sexo se mistura à figuração do ordinário, provocando um transbordamento do sentido, o que termina por retirar da ação sua habitual supremacia no contexto do cinema narrativo.

Muslewski (2013) defende, nessa perspectiva, que a inserção de sequências de caráter sexual no filme tem natureza disruptiva, pois cria um efeito de interrupção, uma censura na apreensão da história por parte do espectador, uma vez que tais cenas guardam, aqui, uma dimensão iminentemente performativa e não contribuem diretamente para o andamento da narrativa. Porém, nosso argumento é de que essa estratégia visa, de fato, promover uma aproximação com o personagem, pois, no filme, essas interrupções operam a fim de mobilizar as sensações do espectador em relação aos corpos dos personagens. Como afirma Mariana Baltar (2013), tal movimento disruptivo se dá “como uma expressão que se ampara no corpo e para o corpo, contudo, um corpo que ultrapassa o desejo de representação, mas que se sustenta na performance (...) como um evento afetivo-expressivo ${ }^{20 "}$ (Baltar, 2013: 70).

Assim, os adolescentes de Ken Park figuram tanto como resultado do meio corrompido no qual vivem, quanto refletem a urgência de escapar de sua triste realidade, seja pelas vias do sexo ou da violência; seja pela afirmação da vida ou pela exaltação à morte. Se, por um lado, Clark solicita do espectador sua adesão à história, à ficção encenada, colocando em cena uma juventude niilista, sem rumo e sem propósito, por outro lado, como bem pontua Muslewski (2013), o cineasta procura abolir qualquer forma de separação ou distanciamento na exploração de seus corpos filmados, reatualizando, assim, de forma perversa, a dimensão tátil da percepção visual.

\footnotetext{
${ }^{20}$ Baltar (2013) fundamenta o termo performance nas ideias de Elena Del Río, ou seja, em oposição à noção de representação, como um evento em que novos fluxos de pensamento e sensação podem emergir.
} 


\section{O Cheiro da Gente}

Em O Cheiro da Gente, Clark deixa os Estados Unidos para fixar-se em Paris. A temática - a adolescência - e o modus operandi de filmar (que oscila entre o documentário e a ficção, com atores não profissionais) são semelhantes àqueles de seus outros trabalhos, mas três novas estratégias nos parecem dignas de nota: a presença do diretor em cena ${ }^{21}$ (que faz dois papéis no filme: Rockstar, o mendigo, e o velho cliente fetichista de Math (Lukas Ionesco), que paga para lamber seus pés); o compartilhamento do gesto de filmar (as imagens feitas pela câmera profissional do diretor são por vezes interrompidas por imagens feitas pela câmera do celular de Toff (Terin Maxime), um dos adolescentes, alter ego do diretor); e a alternância de dispositivos de filmagem (imagens produzidas por celulares, câmeras digitais e webcams se misturam no filme, o que transforma radicalmente, na montagem, a textura dos planos exibidos).

O Cheiro da Gente - filmado mais de dez anos depois de Ken Park e quase vinte anos após Kids - mostra o cotidiano de alguns jovens burgueses da Geração $Z^{22}$, habitantes do XIV arrondissement da capital francesa, que se reúnem atrás do Palais de Tokyo, no Trocadéro, para andar de skate. Inseridos em um cotidiano evasivo, impregnado de álcool, cocaína, pornografia, maconha e jogos de videogame, alguns desses jovens, como JP (Hugo Behar-Thinières) e Math, (uma espécie de releitura de Tadzio de Visconti ${ }^{23}$ ), fazem programa (real ou virtual), isso é, vendem seus corpos ou a imagem deles - a fim de satisfazerem seus desejos de consumo, seja um novo par de botas ou o último modelo de skate. Um corpo que se deixa consumir para consumir. Ao ser descoberto por seus pais e amigos e frustrado pelo amor não correspondido que nutre por Math, JP, desesperado, acaba se suicidando no final do filme, jogando-se da escada do edifício onde trabalha sua madrasta.

\footnotetext{
${ }^{21}$ Apesar de aparecer em cena também em Ken Park, sua participação é bastante rápida e pontual, diferentemente do que ocorre em $O$ Cheiro da Gente, em que o cineasta interpreta dois personagens distintos, um deles, protagonista da trama (Rockstar).

${ }^{22}$ Nome dado à geração nascida entre 1995 e 2000, já inserida na cultura tecnológica e na sociedade em rede.

${ }^{23}$ Personagem da obra Morte em Veneza, adaptação feita pra o cinema por Luchino Visconti, em 1971, do livro homônimo de Thomas Mann (publicado originalmente em 1912).
} 
Assim, $O$ Cheiro da Gente traz em cena um grupo nada orgânico de adolescentes da bourgeoisie française, tipos de uma geração conectada em rede, que tudo registra e tudo compartilha, (como faz Toff), em que "todo mundo é gay", como nota Marie (Diane Rouxel); uma geração que faz do sexo uma moeda de troca e do corpo, uma mercadoria. Assim, parece não haver mais fantasma, nem paraíso, pouco menos redenção possível para esses jovens. A experiência erótica se converte, aqui, em puro dinheiro; é capitalizada, mercantilizada, agenciada. O sexo é tão ou mais explícito que em Ken Park, seja entre os adolescentes, mais preocupados em filmá-lo do que em praticá-lo; seja entre adolescentes e os adultos, que se usam do corpo dos mais novos a fim de realizar suas taras e seus fetiches, a exemplo das sequências que mostram Math com seu cliente podólatra, a lamber-lhe os pés; da mãe alcoólatra, que o assedia de modo incisivo; além de uma triste e longa cena de penetração anal.

Nela, as tomadas se alternam entre o rosto impassível de Math, absolutamente fora de si, deitado numa cama, a olhar fixamente para o teto como se estivera hipnotizado, em transe (Figura 9), e o primeiro plano da penetração propriamente dita, filmada por entre as pernas do cliente que o sodomiza e cujo rosto nos é dado a ver em seguida. Contudo, na metade da sequência, o plano muda de composição, de luz e de textura, ao passo que o rosto de Math também passa a ser registrado por outro ângulo. Trata-se de uma imagem produzida pelo aparelho celular de Toff, que aparece agora em cena, filmando atentamente a relação sexual entre o amigo e seu cliente, enquanto se deixa filmar por Clark. Voltamos a ver, então, o rosto sem expressão de Math, que recebe um tapa do cliente, descontente com a apatia do parceiro. Os movimentos de penetração se intensificam e as imagens metonímicas de seus corpos em movimento pés, pernas, mãos, nádegas, rostos -, a exemplo do que vemos ocorrer em Ken Park, desfilam em uma série de tomadas em primeiros-planos, até que a sequência se termina, mostrando novamente o rosto vidrado e iluminado de Math, captado pela lente de Toff (Figura 10). 


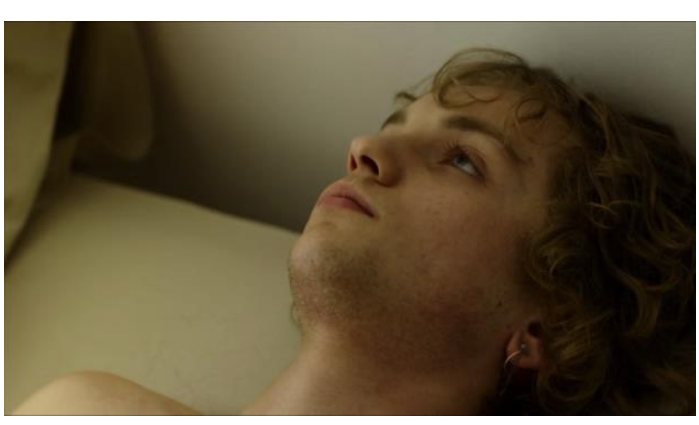

Figura 9

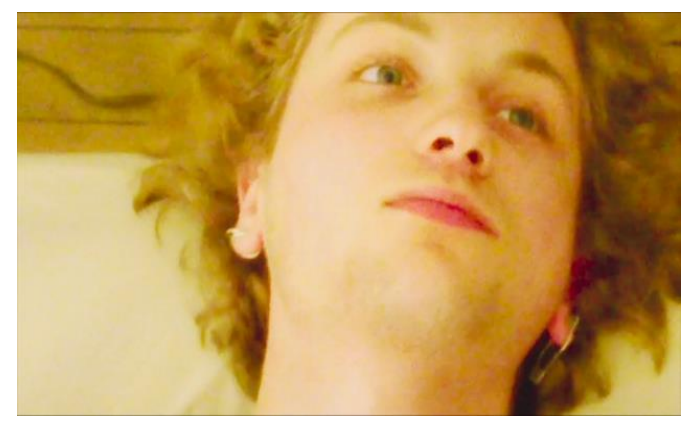

Figura 10

Tudo parece mecânico demais, vazio demais. Não há gozo possível na imagem, nem para os protagonistas ${ }^{24}$, nem para o espectador. Essa impossibilidade de gozar sublinha ainda mais a perversão que conduz o olhar de Clark em $O$ Cheiro da Gente. Aqui, como afirma Luiz Soares Júnior (2015), ao contrário de Kids, as imagens têm um efeito rigorosamente calculado sobre a fobia do corpo pleno, frontal e em terceira dimensão, privilegiando os movimentos e as oscilações de um corpo háptico, cujas partes, fracionadas, não permitem a visão do todo ${ }^{25}$, inserido em uma realidade também multifacetada. O corpo fragmentado e submisso de Math, bem como seu rosto sem expressão denotam, em alguma medida, a ausência de horizonte desses adolescentes, perdidos entre um presente desprezível e um futuro sem perspectiva (o que justifica, na sequência em questão, certo achatamento da câmera em relação ao campo filmado).

Mais do que nos outros dois filmes, em $O$ Cheiro da Gente, Clark dedica especial atenção ao rosto de seus personagens. São várias as tomadas feitas em primeiro plano dos adolescentes durante o filme, captados como se sua juventude, o frescor de seus traços e a vivacidade de suas formas guardassem, por trás de sua superfície plana, um enigma indecifrável que a câmera, ao invés de tentar revelar, se limita apenas a contemplar. Ao discutir a relação entre o rosto, o primeiro plano e o cinema, Gilles Deleuze (2009) considera que "não há grande plano ${ }^{26} d e$ rosto, o rosto é em si mesmo o grande plano; o grande plano é por si mesmo rosto, e ambos são afecto, a imagemafecção" (Deleuze, 2009: 138). Assim, Clark serve-se estrategicamente dos primeiros

\footnotetext{
${ }^{24}$ A longa sequência de sexo termina sem seu clímax. Aliás, nenhuma cena de sexo no filme registra o momento do gozo.

${ }^{25}$ Isso é notável na insistência de Clark em filmar o púbis de Math, com os pelos sempre à mostra, mas cujo calção xadrez vermelho impede o acesso da câmera ao órgão sexual, que o rapaz, de forma provocativa, toca reiteradamente.

${ }^{26} \mathrm{O}$ termo grande plano presente na edição portuguesa da obra de Deleuze deve ser entendido aqui como um sinônimo para primeiro plano.
} 
planos a fim de aproximar o espectador dos personagens, ao mesmo tempo em que constrange e inviabiliza a identificação, pois parece não haver maneira possível de acessar, por meio da câmera, aquilo que estes jovens sentem ou pensam de fato. $\mathrm{O}$ afeto que estes primeiros planos (re)produzem, no caso, é atravessado por algo da ordem da ambiguidade e do estranhamento $^{27}$ (Figuras 11 e 12).

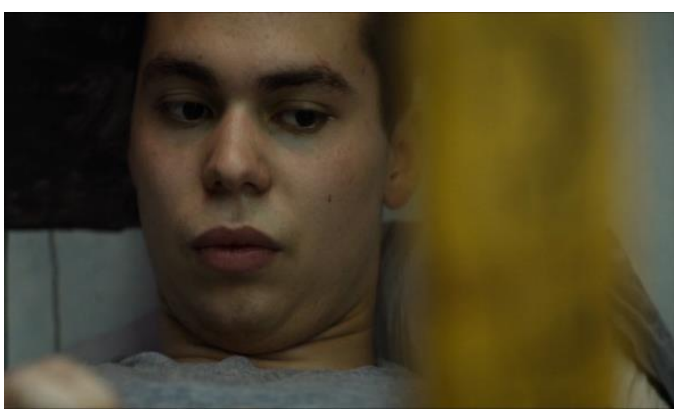

Figura 11

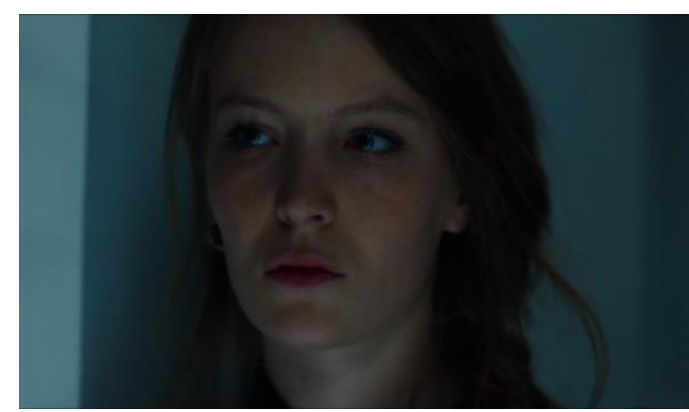

Figura 12

Nessa perspectiva, há de se notar em $O$ Cheiro da Gente, um jogo contínuo de espelhamentos. O mendigo Rockstar, por exemplo, assume uma dimensão metafórica da tragédia da vida adulta, talvez um reflexo daquilo que Math, seu comparsa, se tornará futuramente. A tatuagem em forma de um crânio, de uma caveira, que o jovem carrega no dedo indicador e que Rockstar, inconsciente, deixa marcar em um de seus pulsos indica que aquilo que os une é, de fato, a própria morte (Figura 13). Do mesmo modo, Toff, o garoto que registra tudo pela câmera de seu aparelho celular, que aparece em cena nos momentos mais impróprios ou inesperados, pode ser entendido como uma espécie de alter ego do diretor, uma versão juvenil do próprio Clark, que se infiltra no universo desses adolescentes não mais como um elemento alóctone, como um intruso, mas por meio de um personagem cujo olhar se quer intrínseco e imanente ao grupo, e que nos remete à banalização das imagens em um mundo supermidiatizado.

Em $O$ Cheiro da Gente, assim como em Kids e Ken Park, a perversidade da violência mostra-se onipresente no cotidiano filmado dos adolescentes. A sequência em que Math dopa seu cliente e chama seus amigos para uma festa na casa do homem desacordado é emblemática nesse sentido. Em meio a muita fumaça, bebida, sexo e

\footnotetext{
${ }^{27}$ Esse estranhamento fica ainda mais contundente quando analisamos o personagem de JP, que se suicida no final da história. Em vários momentos do filme, Clark filma o rosto do rapaz por detrás de alguma barreira (a cabeceira da cama - como mostra a figura 11; os ferros do metrô; o corpo de um outro personagem), o que sublinha a dificuldade da câmera em acessar a subjetividade do jovem protagonista.
} 
cocaína - em uma das cenas, Clark filma um jovem esticar e cheirar uma carreira do pó branco no peito de um colega sem camisa (Figura 14) - o cliente, inconsciente, tem o rosto desenhado com injúrias e o corpo todo coberto de penas, enquanto sua casa é saqueada, pixada e depredada.

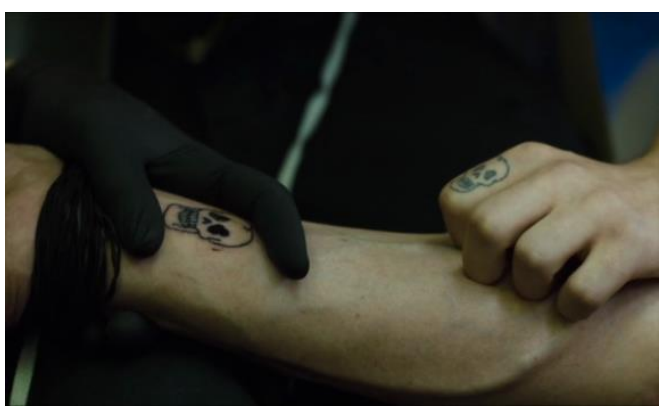

Figura 13

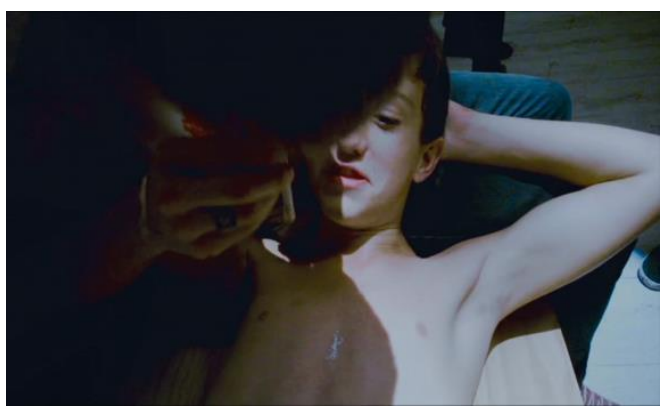

Figura 14

Com efeito, os adultos, em contraposição aos jovens, são retratados em $O$ Cheiro da Gente com um desprezo ainda maior do que em Ken Park, de forma ainda mais patética (eles são feios, velhos, decadentes, quase repugnantes; verdadeiros personagens lynchianos), às vezes até grotesca, a exemplo de Rockstar, que urina nas próprias calças. Ao colocar esses corpos - o jovem e o velho - em relação conflituosa de espelhamento, Clark questiona o tempo que passa e, quiçá, se pergunte “O que, de fato, aconteceu?", ao despertar, assustado, como faz Casper no dia seguinte à festa, na sequência final de Kids. Em última instância, $O$ Cheiro da Gente é mesmo um filme sobre o envelhecer, mais do que sobre a adolescência. Seu cheiro é de morte.

Para alguns críticos (Bradshaw, 2014; Lacuve, 2015), diferentemente dos trabalhos anteriores de Clark, $O$ Cheiro da Gente não fala à juventude contemporânea, pois esses jovens que o diretor filma não são reais, mas personagens de um roteiro, protagonistas de uma ficção milimetricamente ensaiada e encenada, uma suspensão da vida vivida em nome de sua representação. A visão de mundo que o filme enseja também não é suficientemente realista, e, talvez, essa não seja mesmo a intenção do diretor. No filme, a câmera se converte num dispositivo que deseja registrar o artifício, a simulação, as aparências, e ela parece não querer ir além. Pois, quiçá seja esse o verdadeiro lugar da adolescência em nossos dias. 


\section{Considerações Finais}

Por meio de uma visita a três filmes de Larry Clark, tentamos mostrar que sua mise-en-scène é elaborada a partir de uma exageração, tanto temática quanto formal, da intimidade e da degradação, amparada na superexposição do corpo adolescente, registrado de forma erotizada, mas fragmentada, por meio de metonímias visuais. Tal estratégia opera no sentido de conduzir o espectador o mais próximo possível desses jovens para, então, perversamente, barrar seu olhar, colocando-o na posição ambígua de, ao consumir a imagem da intimidade de seus corpos, ser convocado a interrogar-se sobre as modalidades de seu próprio investimento em relação àquilo que mostra o filme. Ver demais não significa tudo ver. O excesso se transforma, aqui, em signo de uma falta constante.

Há, por trás do gesto de filmar, sempre um gesto político. Toda estética pressupõe também uma ética, uma forma de andar pelo mundo, de registrá-lo e de nele intervir. Clark tem a sua, e ela é, como tentamos mostrar, perversa. Perversa, porque estabelece um jogo bastante particular entre a câmera, aquele que se deixa filmar e aquele para quem se filma; entre diretor, personagem e espectador. Porque dessa relação, surge sempre uma imagem que não dá conta daquilo que abarca, que não sustenta aquilo que veicula, assim como os filmes não conseguem dar conta da complexidade do universo no qual vivem esses adolescentes. Diferentemente de seus conterrâneos Gus Van Sant ou de Sofia Coppola, que também se propõem a captar a adolescência, sua essência e seus conflitos intersubjetivos, a poética de Clark está absolutamente vinculada à superfície das coisas, ao corpo, ao sexo e ao erotismo, e deles depende, em larga medida, para colocar-se em cena. Para o diretor, filmar a adolescência é buscar apreender, por meio do cinema, algo da própria vida que escapa; apanhar o tempo que passa. A beleza de seu trabalho subsiste, portanto, na tentativa - destarte frustrada - de explorar esses corpos a fim de conhecê-los melhor, compreendê-los melhor e, com isso, perverter o olhar do espectador e seu desejo de tudo ver. 


\section{Referências}

BALTAR, Mariana. Entre afetos e excessos - respostas de engajamento sensório-sentimental no documentário brasileiro contemporâneo. In: Rebeca - Revista Brasileira de Estudos de Cinema e Audiovisual, ano 2, n. 4, jul-dez 2013, pp.60-85.

BRADSHAW, Peter. The Smell of Us Review: Larry Clark's passionless voyeur flick. In: The Guardian (UK), 31 de agosto de 2014. Disponível em: https://www.theguardian.com/film/2014/aug/31/larry-clark-the-smell-of-us-peter-bradshaw. Consultado em 23 de maio de 2017.

CALVET, Yann; VASSE, David (org). Figures de l'adolescence: Le cinéma en rupture. Unil, Lausanne : Eclipses - Revue de Cinéma, n. 37, janvier 2007.

DELEUZE, G. Logique du sens. Paris : Les Éditions de Minuit, 2002. . Sacher-Moasoch: o Frio e o Cruel. Rio de Janeiro: Jorge Zahar, 2009. . A imagem-movimento: Cinema 1. Lisboa: Assírio \& Alvim, 2009.

DENBY, David. School's out forever. New York Magazine, Nova Iorque, 31 de julho de 1995, pp. 44-45.

GIROUX, Henry. O filme "Kids" e a política de demonização da juventude. UFGRS, Porto Alegre: Revista Educação e Realidade, n. 21 (1), jan-jul 1996, pp. 123-136.

LACUVE, Jean-Luc. The Smell of Us.In: Ciné-club de Caen, 22 janvier 2015. Disponível em: http://www.cineclubdecaen.com/realisat/clark/thesmellofus.htm. Consultado em 23 de maio de 2017.

MUSLEWSKI, Anna."L'image-coupable: haptique du regard dans le cinéma de Larry Clark", Entrelacs [Online], $10 \mid 2013$, Disponível online em: http://entrelacs.revues.org/526. Consultado em 22 de maio de 2017.

O'CONNER, Tom Austin. Genresing Harmony Korine's cinema of poetry. Leeds: Journal Wide Screen Vol 1, Issue 1, April 2009. Pp. 01-16.

OLIVEIRA JR., Luiz Carlos de. "Kids". Contracampo: Revista de Cinema. N. 59/ 1995. Disponível em: http://www.contracampo.com.br/59/kids.htm. Consultado em 21 de maio de 2017.

SOARES JUNIOR, Luiz. The Smell of Us, de Larry Clark (França, 2014). In: Revista Cinética: Cinema e Crítica. 12 de agosto de 2015. Disponível em: http://revistacinetica.com.br/home/thesmell-of-us-de-larry-clark-franca-2014/. Consultado em 23 de maio de 2017.

Recebido em: 29/05/2017. Aprovado em: 21/07/2017. 